\title{
Chronic noncancer pain and the long term utility of opioids
}

\author{
CPN Watson MD FRCPC 1 , JH Watt-Watson RN PhD ${ }^{2}, \mathrm{ML}_{\text {Chipman }} \mathrm{MA}^{3}$
}

CPN Watson, JH Watt-Watson, ML Chipman. Chronic noncancer pain and the long term utility of opioids. Pain Res Manag 2004;9(1):19-24.

OBJECTIVE: To report on a long term experience in treating patients with chronic noncancer pain (CNCP).

METHODS: One hundred two patients with CNCP were seen every three months and followed for one year or more (median eight years, range one to 22). Demographic data, diagnostic categories and response to therapies were recorded. The utility and safety of opioid therapy, adverse events, impact on disability and issues related to previous psychiatric or chemical dependency history were documented. RESULTS: Most patients reported a variety of neuropathic pain problems and most required chronic opioid therapy after the failure of other treatments. Although 44\% reported being satisfied with pain relief despite adverse events, it is noteworthy that the remaining patients chose to continue therapy for the modest benefit of pain relief despite adverse events. Moreover, 54\% were less disabled on opioid therapy.

CONCLUSIONS: This is a large sample of CNCP patients, most taking opioids over a long period of time. CNCP can be treated by opioids safely and with a modest effect, with improvement in functioning in some patients who are refractory to other measures. If care is taken, opioids may even be used effectively for patients with a history of chemical dependency.

Key Words: Chronic noncancer; Neurological practice; Opioid therapy

"Diseases desperate grown

By desperate measures are relieved

Or not at all."

Hamlet IV, iii, 9.

"Opioid analgesics unquestionably provide relief of severe, chronic, unrelieved pain... of non-neoplastic origin.

Arthur Taub 1982 (1)

$\mathrm{M}^{\mathrm{o}}$ ore than two decades ago we began treating patients experiencing chronic noncancer pain (CNCP) with opioids at the Toronto General Hospital. This approach was initiated because chronic pain patients who were refractory to all other measures told us that this was the only avenue of some relief for them. We were bolstered by controlled trials of oral opioids in cancer pain, our own empirical experience with a variety of opioids in malignancy-related suffering, and Arthur Taub's report (1). Because this therapy was controversial at the

\section{La douleur non cancéreuse chronique et l'utilité à long terme des opioïdes}

OBJECTIF : Présenter un compte rendu d'une expérience prolongée dans le traitement de patients atteints de douleur non cancéreuse chronique (DNCC).

MÉTHODOLOGIE : Cent deux patients souffrant de DNCC ont été vus tous les trois mois et suivis pendant au moins un an (médiane de huit ans, fourchette entre un et 22 ans). Les données démographiques, les catégories diagnostiques et les réponses aux traitements ont été prises en note. Lutilité et l'innocuité de l'opioïdothérapie, les effets indésirables, les répercussions sur l'invalidité et les questions reliées à une dépendance précédente à la psychiatrie ou aux produits chimiques ont été documentés.

RÉSULTATS : La plupart des patients ont déclaré des troubles de douleur neuropathique, et la plupart avaient besoin d'une opioïdothérapie après l'échec d'autres traitements. Bien que $44 \%$ se soient dits satisfaits du soulagement de la douleur malgré les effets indésirables, il convient de souligner que les autres patients ont choisi de poursuivre le traitement en raison du bénéfice modeste de soulagement de la douleur, malgré les effets indésirables. De plus, $54 \%$ des patients étaient moins invalides sous opioïdothérapie.

CONCLUSIONS : C'est un vaste échantillon de patients atteints de DNCC, dont la plupart prenaient des opioïdes depuis une longue période. La DNCC peut être traitée à l'aide d'opioïdes en toute innocuité et procurer un effet modeste, assurant une amélioration du fonctionnement chez certains patients réfractaires à d'autres mesures. Si des précautions sont prises, il est possible d'utiliser les opioïdes avec efficacité auprès des patients ayant des antécédents de chimiodépendance.

time, we began recording data on all patients who attended this clinic. This report is a distillation of that 21-year experience.

CNCP problems are the most common disorders seen in neurological practice (2). The most frequent manifestations of CNCP encountered in this setting are headache, musculoskeletal disorders and neuropathic pain of varied causes (2). $\mathrm{CNCP}$ can be challenging to treat effectively. A few reports have documented significant pain relief with the long term use of opioids in CNCP (1,3-5). Some of these studies include neuropathic pain (1) and report improvement in performance status (5).

The purpose of this study was to survey a population of patients with CNCP, who were being followed by a neurologist (CPN Watson), with regard to the long term efficacy of different therapies. In this paper, issues of specific interest related to opioid therapy are discussed and include the following: the utility and safety of chronic opioid therapy; the impact on pain-related disability; the frequency of drug seeking behav-

\footnotetext{
${ }^{1}$ Faculty of Medicine, University of Toronto; ${ }^{2}$ Faculty of Nursing, University of Toronto; ${ }^{3}$ Department of Public Health Sciences, University of Toronto, Toronto, Ontario

Correspondence: Dr CPN Watson, 1 Sir Williams Lane, Toronto, Ontario M9A 1T8. Telephone 416-239-3484, fax 416-239-6365
} 
TABLE 1

Diagnostic categories of patients*

\begin{tabular}{lc}
\hline Category & Number \\
\hline Neuropathic (n=81) & 23 \\
Back and leg (nerve root) & 18 \\
Atypical facial (neuropathic) & 15 \\
Postherpetic & 6 \\
Trigeminal neuralgia & 5 \\
Central neuropathic & 4 \\
Generalized neuropathy & 3 \\
Pelvic neuropathic & 2 \\
Phantom limb & 2 \\
Brachial plexopathy & 2 \\
Incisional neuralgia & 1 \\
Sural (post-traumatic) neuropathy & \\
Headache (n=20) & 16 \\
Chronic daily & 4 \\
Cluster & \\
Arthritis/arthropathy (n=13) & \\
Osteoarthritis, Crohn's disease, lupus, sickle cell, \\
$\quad$ osteoporosis, osteogenesis imperfecta
\end{tabular}

*12 patients had two pain diagnoses

iour, tolerance and physical withdrawal; previous psychiatric history; and the importance of the use of guidelines and documentation with scrutiny by a regulatory body.

\section{METHODS}

\section{Research design and sample}

Data were collected over a 21-year period from consenting patients with CNCP who were being followed by a neurologist (CPN Watson). Patients were seen regularly, at intervals of about three months, and were followed for at least one year (median eight years). All had rated their daily pain as moderate to severe when seen at the initial visit.

\section{Procedure}

Guidelines for opioid prescribing and documentation were used by the physician in all cases, although patients were not required to sign a written contract. Verbal guidelines were carefully outlined with all patients. The guidelines particularly emphasized with patients included the use of a single prescriber and pharmacy, and regular visits to the physician (at least every three months). Guidelines implemented by the physician included carbon copies of the prescription and documentation of pain status with and without opioids, level of activity, side effects, drugs and drug dosage. All patients were asked about their previous drug and alcohol use.

Outcomes that were recorded included pain severity, amount of pain relief, disability, adverse events and satisfaction. A report was sent to the referring physician and a carbon copy of the prescription was affixed to the chart. A standard treatment approach was followed with some variability depending on the diagnosis and previous therapy. Most patients were given trials of at least two antidepressants, anticonvulsants and nonsteroidal anti-inflammatories, and some were given other categories of drugs as well. Patients with refractory pain were offered chronic opioid therapy, and trials of several different long and short acting opioids were used when necessary.

With all agents a 'start low and go slow' approach was generally taken. The agent was slowly increased to maximal therapeutic effect or intolerable adverse events before moving on to the next treatment. Initially patients were seen weekly or bi-weekly until they were stable and then at intervals of about three months.

\section{Outcome measures}

Data collected at the first baseline interview included demographic and diagnostic information, including pain duration, quality and location. Pain severity was measured using a category scale of mild, moderate, severe or very severe, and a zero to 10 numerical rating scale (NRS). Disability related to pain was measured using a categorical scale ( $\mathrm{mild}=$ cannot exercise, moderate $=$ cannot work, severe $=$ usual home/childcare activities only, very severe=bedridden or self-care only). At subsequent follow-up visits, data were collected to measure pain severity (category scale of mild, moderate, severe, very severe), pain relief (NRS, $0 \%$ to $100 \%$ ), adverse events (open-ended enquiry), disability (categorical scale as above) and satisfaction with pain relief (yes/no). Data were also collected about the frequency of drug seeking behaviour, tolerance and physical withdrawal; the use of opioids with patients having a previous psychiatric history; the guidelines used and the results of scrutiny by the College of Physicians and Surgeons of Ontario, the provincial regulatory body.

Descriptive statistics were used to describe the sample's demographic characteristics and diagnostic categories. As well, descriptive statistics (ie, averages, SDs, proportions) were used to summarize outcome variable data.

\section{RESULTS}

\section{Demographics and diagnostic categories}

One hundred two patients were seen at intervals of three months or less and followed from one to 22 years (median eight years). The sample included 53 females and 49 males with a mean age of 51 years.

Table 1 illustrates the diagnostic categories regarding the 102 patients in this sample. The largest group of patients consisted of those with neuropathic pain, most frequently neuropathic failed back syndrome or facial pain. The other two main groups were patients with chronic daily headache or arthritis/ arthropathy. Twelve patients had pain in two diagnostic categories.

\section{Utility and safety of chronic opioid therapy}

The utility and safety of chronic opioid therapy were determined by the change in pain severity by the final visit, satisfaction with pain relief and adverse events.

Pain and satisfaction with relief: Approximately one-third of patients (34 out of 102) had a change in their pain status from either severe or moderate pain to mild pain, as measured by a zero to $10 \mathrm{NRS}$ (mild=one to three, moderate $=$ four to seven, severe=eight to 10), by a category scale (absent, mild, moderate, severe, very severe) and by considering pain with movement. 
About $60 \%$ of patients (60 out of 102) had a change from severe pain to moderate pain, and eight (9\%) were unchanged. Patients were asked whether they were satisfied with pain relief despite experiencing adverse events; 45 patients (44\%) responded they were satisfied but 57 (56\%) indicated they were not satisfied.

Adverse events: Fifty-three per cent of patients $(n=55)$ did not experience significant drug-related adverse events. However, of those patients reporting significant adverse events $(n=47)$, nearly $66 \%$ (34 out of 47 ) indicated that these were intolerable, which was about $30 \%$ of the total group $(n=102)$. The events identified were typical of opioids (ie, constipation and nausea). For example, constipation occurred in all patients receiving these drugs, and management was tailored to the individual using dietary fiber, stool softeners, bulk enhancers, bowel stimulants, enemas and, in some cases, the intermittent employment of the bowel preparations used for colonoscopy. Nausea occurred often with the initiation of opioids even on occasion with low doses and was managed with a variety of antinauseants. Nausea usually ceased to be a problem as tolerance developed to this symptom. Preemptive use of antinauseants and treatment for constipation was the rule to try to minimize these problems. With one patient who was refractory to all other agents for nausea, a cannabinoid was used (nabilone). Drowsiness was infrequent with the long term use of opioids. In Ontario, there is a legal obligation to notify the provincial ministry of transportation if a physician feels a driver is unsafe. This occurred on only one occasion and was because of drowsiness.

Therapeutic approaches: Table 2 documents the drugs most commonly used by patients who reported at least moderate relief (a change from severe/very severe to mild/moderate pain). Table 3 documents patients' drug preference for pain relief when given alone or with an adjuvant by the last visit. Most patients ( $n=90$, $88 \%$ ) required an opioid for maximum relief and most patients $(n=92,90 \%)$ used more than one opioid or an opioid plus an agent in another category, such as an antidepressant or anticonvulsant. The most frequently identified opioid preference for pain relief (Table 3 ) was oxycodone $(n=33)$ in a variety of forms, followed by morphine $(n=21)$, transdermal fentanyl $(n=20)$, hydromorphone $(n=6)$, codeine combined with acetaminophen $(n=5)$, intramuscular meperidine $(n=1)$ and anileridine $(n=1)$. The patient using intramuscular meperidine had been taking this for five years previously for managing pain from fractures due to osteogenesis imperfecta. He had tried many oral agents unsuccessfully and it was decided to maintain this approach because it was safe and effective for him.

\section{Impact on pain-related disability}

Of particular interest was the effect of chronic opioid therapy on patients' pain-related disability (ie, bedridden, self-care, usual home/childcare activities, exercise, work) (Figure 1). Of the 86 patients assessed for disability, eight had no change in pain or disability and remained in the bedridden or self-care only category. However, of the $91 \%(n=78)$ of patients whose pain improved on opioids, 47 patients had significant improvement in their disability status. These patients changed from being
TABLE 2

Drugs used in those patients achieving at least moderate relief*

\begin{tabular}{|c|c|c|c|}
\hline$P^{\prime}$ & $\begin{array}{l}\text { Patients } \\
\text { using } \\
\text { drug (n) }\end{array}$ & $\begin{array}{c}\text { Dose } \\
\text { (median) }\end{array}$ & Range \\
\hline \multicolumn{4}{|l|}{ Opioids } \\
\hline Transdermal fentanyl & 21 & $\begin{array}{l}100 \mu \mathrm{g} / \mathrm{h} \\
\mathrm{q} 3 \text { days }\end{array}$ & $\begin{array}{l}25 \text { to } 175 \mu \mathrm{g} / \mathrm{h} \\
\mathrm{q} 3 \text { day }\end{array}$ \\
\hline Oxycodone-acetaminophen & 26 & 6 tabs/day & 2 to 10 tabs/day \\
\hline Oxycodone-ASA & 1 & 6 tabs/day & \\
\hline Oxycodone & 7 & $30 \mathrm{mg} / \mathrm{day}$ & 10 to $60 \mathrm{mg} / \mathrm{day}$ \\
\hline Sustained release oxycodone & 21 & $180 \mathrm{mg} / \mathrm{day}$ & 30 to $900 \mathrm{mg} /$ day \\
\hline Sustained release morphine & 11 & $60 \mathrm{mg} / \mathrm{day}$ & 30 to $180 \mathrm{mg} /$ day \\
\hline Morphine tablets & 13 & $500 \mathrm{mg} /$ day & 30 to $2800 \mathrm{mg} /$ day \\
\hline $\begin{array}{l}\text { Acetaminophen with codeine, } \\
8 \mathrm{mg}, 15 \mathrm{mg}, 30 \mathrm{mg} \text { and } 60 \mathrm{mg}\end{array}$ & $\mathrm{mg}^{8}$ & 4 tabs/day & $2-10$ tabs/day \\
\hline Codeine & 1 & $45 \mathrm{mg} /$ day & 30 to $60 \mathrm{mg} /$ day \\
\hline $\begin{array}{l}\text { ASA-caffeine, butabarbitol } \\
\text { with codeine } 30 \mathrm{mg}\end{array}$ & 4 & 1 cap/day & 1 to 3 cap/day \\
\hline Hydromorphone & 5 & 4 mg/day & 2 to $8 \mathrm{mg} /$ day \\
\hline Sustained release hydromorphone & ne 3 & $24 \mathrm{mg} / \mathrm{day}$ & 6 to $48 \mathrm{mg} / \mathrm{day}$ \\
\hline Anileridine & 3 & 75 mg/day & 50 to $100 \mathrm{mg} /$ day \\
\hline Meperidine & 3 & 200 mg/day & 100 to $600 \mathrm{mg} / \mathrm{day}$ \\
\hline \multicolumn{4}{|l|}{ Antidepressants } \\
\hline Nortriptyline & 12 & $50 \mathrm{mg} / \mathrm{day}$ & 10 to $100 \mathrm{mg} /$ day \\
\hline Amitriptyline & 10 & $50 \mathrm{mg} / \mathrm{day}$ & 20 to $75 \mathrm{mg} /$ day \\
\hline Doxepin & 1 & $50 \mathrm{mg} / \mathrm{day}$ & $50 \mathrm{mg} / \mathrm{day}$ \\
\hline Lithium & 1 & $900 \mathrm{mg} / \mathrm{day}$ & $900 \mathrm{mg} / \mathrm{day}$ \\
\hline
\end{tabular}

\begin{tabular}{lll}
$\begin{array}{l}\text { Anticonvulsants } \\
\text { Carbamazepine } \\
\text { Gabapentin }\end{array}$ & 7 & $600 \mathrm{mg} /$ day 200 to $2400 \mathrm{mg} / \mathrm{day}$ \\
Other & 1 & $1200 \mathrm{mg} / \mathrm{day}$ \\
Sumatriptan & 1 & $200 \mathrm{mg} / \mathrm{day}$ \\
Dihydroergotamine & 1 & $\mathrm{prn}$ \\
Ergotamine & 1 & $\mathrm{prn}$ \\
Buprenorphine & 1 & $\mathrm{prn}$ \\
Verapamil & 2 & $320 \mathrm{mg} /$ day \\
Propranolol & 2 & $160 \mathrm{mg} /$ day \\
Flunarizine & 1 & $10 \mathrm{mg} /$ day \\
Naproxen & 1 & $250 \mathrm{mg} /$ day \\
Tramadol & 1 & $150 \mathrm{mg} /$ day \\
None & 6 & \\
\hline
\end{tabular}

*Many patients used more than one drug. ASA Acetylsalicylic acid; prn As needed; $q$ Every; tabs Tablets

bedridden or only capable of self-care to being able to complete at least usual household/childcare activities and eight patients returned to work. Of the remaining 31 patients whose pain improved with no change in disability, a ceiling effect was present for 23 patients who at baseline were either working or at least able to carry on usual home/childcare activities.

Drug seeking behaviour, tolerance and physical withdrawal Chemical dependency and pseudo-addiction: Eleven patients exhibited signs of drug seeking behaviour. These individuals demonstrated demands for escalating doses of opioid despite 
TABLE 3

Patient drug preference.

\begin{tabular}{llc}
\hline Category & Drug & Patients (n) \\
\hline Opioids & Transdermal fentanyl & 20 \\
& Oxycodone acetaminophen & 20 \\
& Sustained release morphine & 16 \\
& Sustained release oxycodone & 7 \\
& Oxycodone & 5 \\
& Morphine tablets & 5 \\
& Acetaminophen with codeine, & 5 \\
& 8 mg, 15 mg, 30 mg and 60 mg & \\
& Hydromorphone & 4 \\
& Sustained release hydromorphone & 2 \\
Antidepressants & Anileridine & 1 \\
& Oxycodone-ASA & 1 \\
& Meperidine & 1 \\
Nortriptyline & 9 \\
Other & Amitriptyline & 1 \\
& Fluoxetine & 1 \\
None & Carbamazepine & 5 \\
\hline Pationt & Clonazepam & 1 \\
& Lithium & 1 \\
& Baclofen & 1 \\
& Sumatriptan & 1 \\
& - & 8 \\
& - & 10 \\
\end{tabular}

Patient ranking of preferred opioids was oxycodone (33), morphine (21), transdermal fentanyl (20), hydromorphone (6), codeine (5), anileridine (1), meperidime (1). Some patients gave more than one preference. ASA Acetylsalicylic acid

evidence of a stable, chronic pain state. A variety of excuses were put forward by patients to justify replacement prescriptions. Secretive double doctoring occurred as well as prescription forging and visits to two or more pharmacies. All 11 patients ultimately admitted that they took the drugs for the effect on mood; all individuals had a known history of chemical dependency. In six instances, prescribing was stopped, including three patients with chronic, daily headache. However, in five cases, prescription continued after guidelines were again carefully reviewed with them, and these patients have been on stable opioids for at least three years with benefit. One other patient's cause for prescription forging was determined to be pseudo-addiction (inadequate dosing for pain relief). She has had moderate relief of chronic headache and phantom finger pain on a stable higher opioid dose for six years since this event.

Physical dependency: Because most patients were not withdrawn from opioids, it was not possible to reliably assess this.

Tolerance: There were 15 different opioid preparations in 68 patients and the dosage prescribed remained the same for a median of three years (range one to 20) after the achievement of maximal relief and tolerable side effects. Escalating doses, in the authors' view, usually (with two exceptions) represented psychological dependency in the face of a chronic, stable pain state.

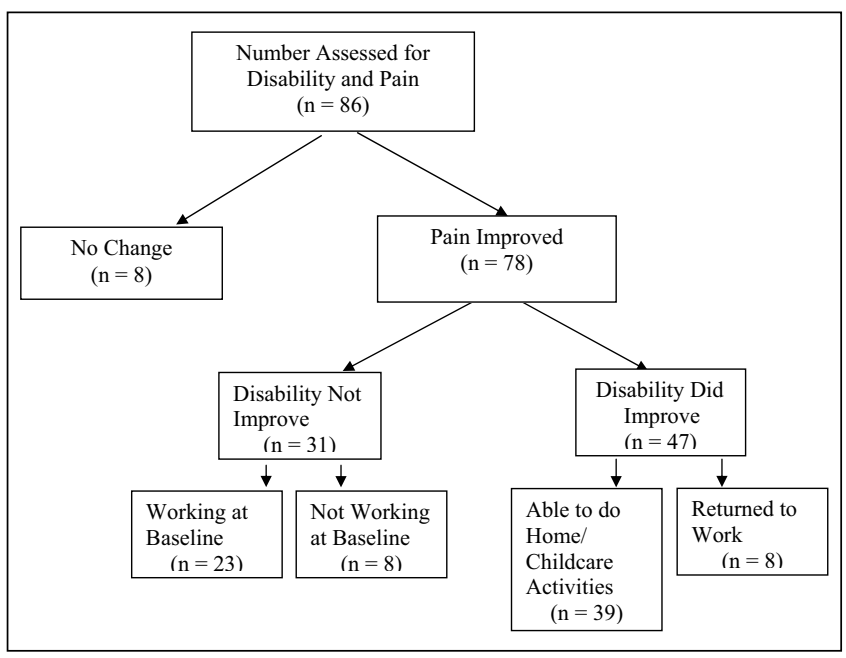

Figure 1) Disability status (home/childcare, work, exercise) for patients whose pain relief improved on opioids

\section{Psychiatric history}

Suicide: One 50-year-old male patient with no psychiatric history committed suicide with clonazepam. This occurred after marital difficulties, probably precipitated by severe, unrelieved pain.

Previous psychiatric history: Eight patients had, at first contact, a history of psychiatric treatment for either severe depression $(n=6)$, schizophrenia $(n=1)$ or bipolar disorder $(n=1)$. Only with the latter was there an issue of a manic episode and excessive opioid use; this resolved with the treatment of the psychosis and she has now been well controlled with opioids for five years with no problems.

Importance of guideline use and documentation with regulatory bodies

During this study, an investigation of this neurological practice was carried out by a regulatory body, The College of Physicians and Surgeons of Ontario, because of a complaint by an unknown party. Initially, this was carried out by a retired police officer, and charts were being reviewed by a general practitioner and an internist. Neither was an expert in pain management. The physician (CPN Watson) insisted that the charts be peerreviewed instead by pain experts who were subsequently involved. The inquiry was dropped largely because of good record keeping, including the use of documented guidelines and copies of prescriptions, and favourable expert opinion. Guidelines were used in all cases, although a written opioid contract was not required. Records were kept of prescription copies and outcomes recorded at each visit for pain, treatment, pain relief, disability, adverse events, mood and satisfaction, and a report was sent to the referring physician after each visit.

\section{DISCUSSION}

There are few long term studies of CNCP that focus particularly on opioids in neurological practice $(1,3-5)$. Taub (1), a neurosurgeon, reported in 1982 a large series of 313 CNCP patients who were maintained on opioids for up to six years. However, the number with neuropathic pain was not stated. 
He used the opioids available at the time, including oxycodone (41\%), methadone (19\%), codeine (26\%), and meperidine (12\%) in modest, maximum doses of $40 \mathrm{mg}$ morphine equivalents. Taub concluded that only $4.2 \%$ of patients were a significant management problem due to abuse. No data were given regarding improvements in functioning. He reported that adverse events and tolerance were unusual. He concluded that opioids for $\mathrm{CNCP}$ were reasonable and feasible, that neither organ toxicity nor psychological problems were significant and that there were no significant problems in using opioids to control pain.

In 1986, Portenoy and Foley (3), both neurologists, reported a small series of CNCP patients treated with opioids. Of the 38 patients in this sample, 10 experienced neuropathic pain. Nineteen patients were followed for more than four years and six for seven years or longer. The drugs used included oxycodone $(\mathrm{n}=12)$, methadone $(\mathrm{n}=7)$, levorphanol $(\mathrm{n}=5)$, methadone/ oxycodone $(\mathrm{n}=2)$, propoxyphene $(\mathrm{n}=2)$, propoxyphene/ oxycodone $(\mathrm{n}=2)$, meperidine $(\mathrm{n}=2)$, codeine $(\mathrm{n}=2)$, pentazocine $(n=1)$, pentazocine/propoxyphene $(n=1)$ and levorphanol/codeine $(n=1)$. Oxycodone was used in a total of 17 patients. The dose was $20 \mathrm{mg} /$ day morphine equivalents in two-thirds of patients and more than $40 \mathrm{mg} / \mathrm{day}$ in four patients. The relief was partial and acceptable or fully adequate in 24 of 38 patients, and inadequate in 14 patients. Few substantial gains were made in the patients' employment or social functioning. The authors concluded that opioids were safe and salutary in refractory patients with no history of drug abuse.

In 1988, Tennant and colleagues (4) described 52 patients with CNCP treated with opioids. Two patients were identified as having neuropathic pain. Follow-up by the authors was a mean 30 months, but patients had been on opioids for an average of 12 years before they were seen by the authors. Drugs used were codeine $(n=18)$, methadone $(n=14)$, propoxyphene $(n=7)$, hydromorphone $(n=7)$, oxycodone $(n=5)$, meperidine $(n=4)$, morphine $(n=3)$ and hydrocodone $(n=1)$. Doses taken ranged up to $200 \mathrm{mg}$ morphine equivalents per day. In 46 of 52 patients $(88.6 \%)$, pain control was reported as adequate. No data were given regarding functioning. With nine of 52 patients $(17.3 \%)$, treatment was terminated because of abuse. No escalation was observed in the others after stabilization. The authors concluded that opioids were safe and effective with CNCP if patients were followed closely with frequent clinic visits and monitoring.

In 1992, Zenz and colleagues (5) reported on a patient sample $(n=100)$ with predominantly neuropathic pain and back pain who were followed for an average of 224 days. Patients were treated with dihydrocodeine, buprenorphine or morphine in a dose range of $20 \mathrm{mg}$ to $2000 \mathrm{mg}$ of oral morphine equivalents daily. More than $50 \%$ relief was achieved by 51 patients with $25 \%$ to $50 \%$ improvement in $28 \%$ of patients. Pain relief was associated with a significant improvement in performance status. No cases of psychological dependency or serious side effects were reported.

These studies provide support for the safety and long term relief of modest doses of opioids for some patients with CNCP. Some of the drugs (meperidine, propoxyphene, pentazocine) used in these studies are no longer thought to be appropriate for extended use. More long term data are now needed regarding long acting opioid preparations that were not available at the time of these reports. Our study, therefore, provides long term information, from a large population with predominantly neuropathic pain, about such preparations, including their effica$\mathrm{cy}$, side effects and effect on functioning. This study describes a cohort who chose to return for follow-up by a neurologist and who, as expected, had predominantly chronic pain of neurological origin and were taking chronic opioid therapy. Patients were followed at intervals of about every three months. Most patients were referred because they had failed other therapies for intractable pain. Many were referred by neurologists and other specialists as well as family physicians. Most patients required opioids for relief and continued with extended followup because they stated that their family physician did not wish to prescribe opioids. A number of patients were lost to followup, some were unresponsive to therapy and chose to stop appointments, and some continued to be treated by their family physicians successfully. It is probable that some patients did not return because their family physician was comfortable prescribing antidepressants, gabapentin, and other nonopioid approaches that the patients found useful.

Most of these patients had neuropathic pain diagnoses, as expected in a neurological practice. The use of opioids for neuropathic pain has come to have a scientific basis with the publication of randomized controlled trials in postherpetic neuralgia $(6,7)$. However, little long term information is available regarding efficacy and safety (1,3-5). Most of our patients had at least moderate improvement in pain with chronic opioid therapy, as expected in a group that chose to return to follow-up over a long period of time. It may be important to note that most patients chose oxycodone as the most preferred opioid. One-half of patients had significant adverse events, which at least two-thirds reported as intolerable. Although $44 \%$ of patients reported being satisfied with relief despite adverse events, it is noteworthy that the others chose to continue therapy for the often modest benefit of pain relief despite adverse events.

An important finding is that over one-half of patients (47 of $86,54 \%$ ) were less disabled on therapy with opioids. (Figure 1). This outcome is of particular interest because it has not been previously clear that opioids can improve quality of life with chronic use. Forty-seven patients (54\%) changed from being bedridden or only capable of self-care to an improved activity status. Most improvement was noted in the patients' ability to perform the activities of daily living related to home and childcare. Although $36 \%$ of patients (31 of 86 ) stated that their activity was unchanged, 10 were working and 13 were active in the activities of daily living before and after treatment. Few patients $(n=11)$ exhibited drug seeking behaviours despite the lack of any formal screening tool for this. All of these 11 patients were known to have a history of chemical dependency but also had severe, chronic neurological pain problems. Three of the six patients, for whom prescribing opioids was discontinued, had chronic, daily headaches. In five of these patients, prescribing continued after careful consideration and a review of the guidelines with these individuals. One additional patient was found to have pseudo-addiction behaviour due to underprescribing of the opioid and is stable now with an increase in dosage. Tolerance was rarely observed and an 
increase in dosage in our view usually reflected psychological dependency, or more rarely, a changing pain status due to the underlying disease or a change in activities. Physical dependency could not be assessed because patients were not withdrawn from opioid treatment. Suicide was rare and occurred with one patient.

Despite reasonable attempts at relief with other pharmacological and nonpharmacological therapies, most patients required chronic opioid therapy, and physicians need to learn how to use these agents to adequately treat this type of patient. The variety of types and doses of opioids are notable. These agents were only employed after sequential trials of several alternative medications. As well, patients frequently preferred a combination of opioids, often one long acting and another for breakthrough or incident-related pain. Combinations of long acting opioids were sometimes employed. High doses were sometimes necessary. These observations probably reflect individual variability and differences in opioid pain inhibiting mechanisms.

Most patients chose an opioid when asked which agent they preferred regarding relief and untoward effects. Patients chose a variety of opioids as their most preferred (Table 3); however, the most frequently cited was oxycodone which was preferred in some form by 33 patients, followed by morphine $(n=21)$, transdermal fentanyl $(n=20)$, hydromorphone $(n=6)$, codeine combined with acetaminophen $(n=5)$, meperidine $(n=1)$ and anileridine $(n=1)$ (not all patients tried all opioids listed). Antidepressants and anticonvulsants were infrequent choices as the most preferred drug over the long term for this sample. However, those patients who chose to discontinue follow-up may have been managed satisfactorily with these adjuncts and continued with their family physician for prescription refills.

\section{CONCLUSION}

The long term management of CNCP has been a rewarding part of this neurological practice. It requires the physician to have a basic knowledge of the use of opioids and their current forms. Many patients will only benefit from this approach, which is moderately effective, safe and improves quality of life for many of these sufferers. The use of guidelines (8) for chronic opioid therapy and good record keeping is essential. A variety of opioids of varying dose (which can sometimes be quite high) may be needed to be sequentially employed to determine the agent or agents that afford optimal relief. As well, combination therapy with different opioids or another drug, such as an antidepressant or anticonvulsant, may be necessary. Adverse events were frequent and often reported as difficult to tolerate. Preemptive treatment for constipation is critical because tolerance to constipation does not occur with chronic opioid use and this therapy is necessary on an ongoing basis. Psychological dependence leading to cessation of opioid therapy (only $6 \%$ of this sample) and tolerance to the analgesic effect are infrequent phenomena. Opioids can be prescribed even to some patients with a history of chemical dependency who have a severe pain problem if care is taken and close follow-up is maintained.

\section{REFERENCES}

1. Taub A. Opioid analgesics in the treatment of chronic intractable pain of non-neoplastic origin. In: Kitahata LM, Collins D, eds. Narcotic Analgesics in Anaesthesiology. Baltimore: Williams and Wilkins, 1982:199-208.

2. Kurtzke JE. Neuroepidemiology. Neurology 1984;16:265-77.

3. Portenoy RK, Foley RM. Chronic use of opioid analgesics in non-malignant pain. Report of 38 cases. Pain 1986;25:171-86.

4. Tennant FS, Robinson D, Sagherian A, Seecof R. Chronic opioid treatment of intractable non-malignant pain. Pain Management 1988;81:18-36.

5. Zenz M, Strumpf M, Tryba M. Long-term oral opioid therapy in patients with nonmalignant pain. J Pain Symptom Manag 1992;7:69-77.

6. Watson CPN, Babul N. Efficacy of oxycodone in neuropathic pain: A randomized controlled trial in postherpetic neuralgia. Neurology 1998;50:1837-41.

7. Raja SN, Haythornethwaite JA, Papagallo M, et al. Opioids versus antidepressants in postherpetic neuralgia: A randomized placebocontrolled trial. Neurology 2002;59:1015-21.

8. Portenoy R. Opioid therapy for chronic nonmalignant pain. Pain Res Manage 1996;1:17-28. 


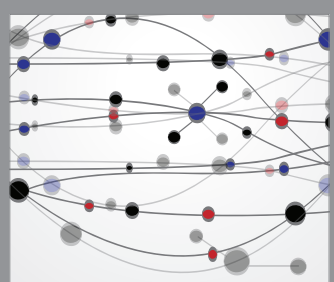

The Scientific World Journal
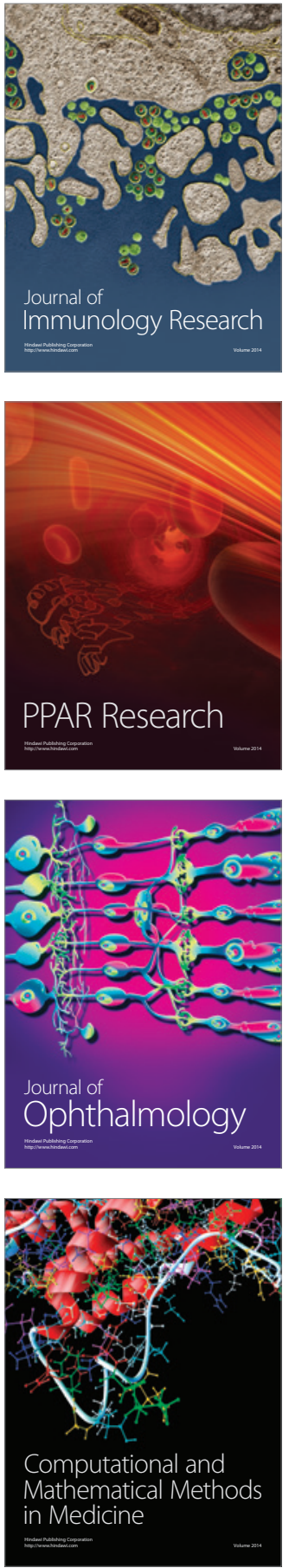

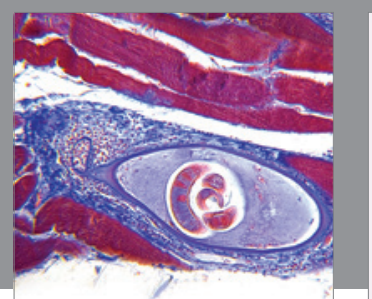

Gastroenterology Research and Practice

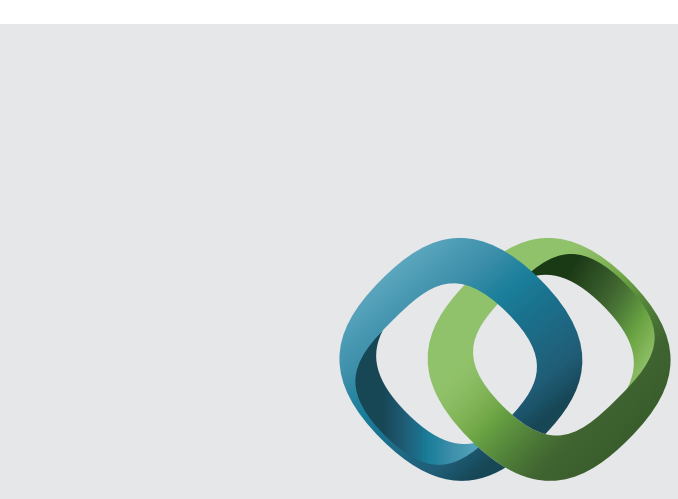

\section{Hindawi}

Submit your manuscripts at

http://www.hindawi.com
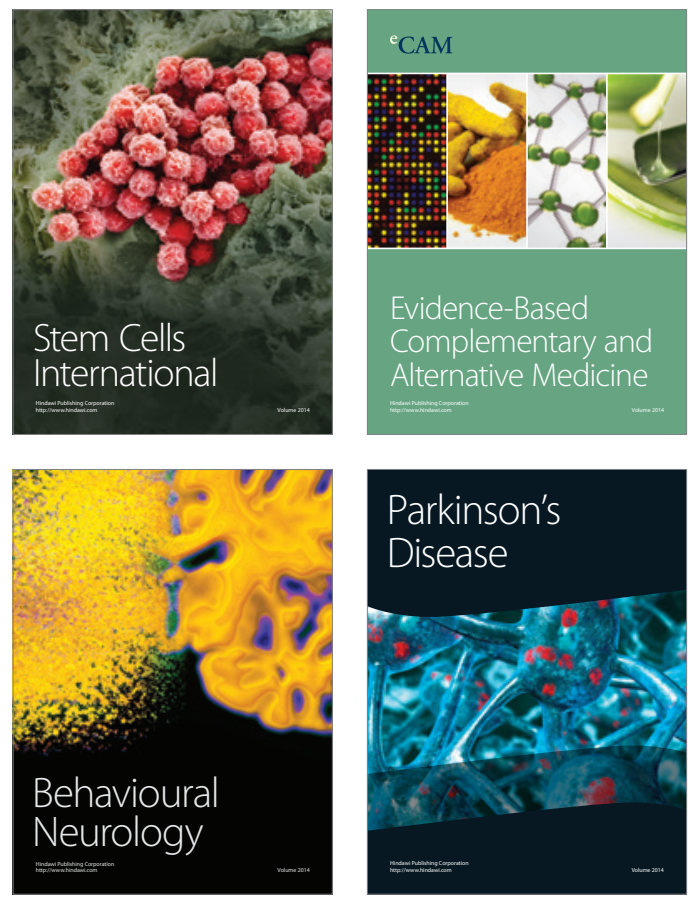
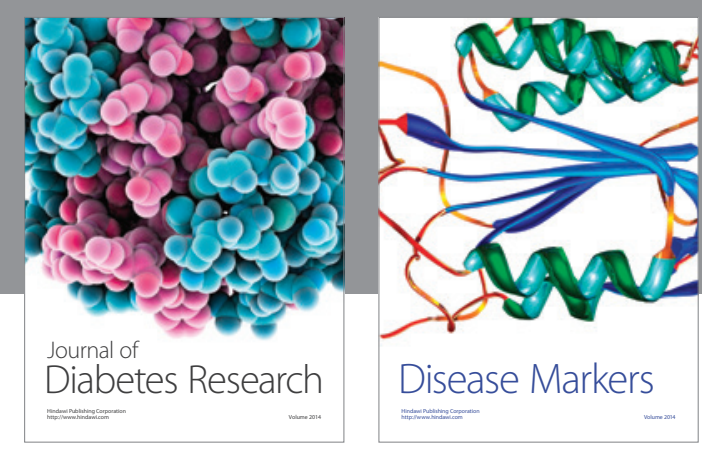

Disease Markers
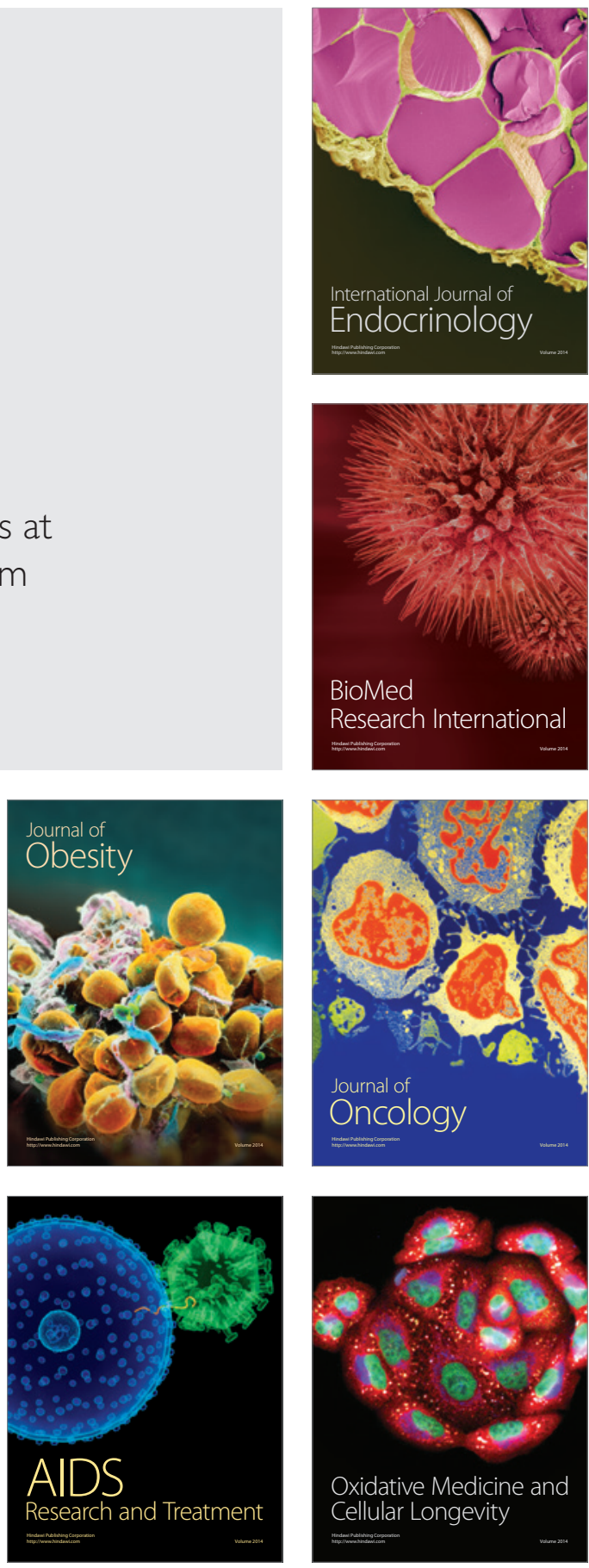